\title{
A devastação no masculino e a violência contra o feminino nas mulheres
}

\section{Devastation in the masculine and violence against feminine in women}

\author{
Denise Maurano Mello*1 \\ Joana Dark da Silva Souza*2
}

O presente artigo tem como objetivo trazer algumas contribuições da psicanálise para o esclarecimento da questão da violência contra a mulher, um fenômeno que se repete na história das sociedades. Buscando pensar sobre as bases estruturais dessa violência, recorremos à teoria lacaniana dos gozos fálico e gozo Outro, feminino, propondo uma diferenciação entre o que se supõe como gozo Outro e o que se estabelece como gozo do Outro. Seguindo o caminho aberto por Lacan, lançamos a hipótese de que o gozo do Outro pode estar relacionado com a vivência no sujeito posicionado do lado do masculino, de um gozo intrusivo e devastador atribuído a um Outro vivido como absoluto, mobilizando reações misóginas e mesmo feminicidas. Tal distinção foi operativa no sentido de nos possibilitar pensar no que aqui designamos como "devastação no masculino" e sua possível relação com o que no artigo discernimos como "violência contra o feminino na mulher". Palavras-chave: Devastação, feminino, masculino, gozo

*1, 2, Universidade Federal do Estado do Rio de Janeiro - UNIRIO (Rio de Janeiro, RJ, Brasil). 


\section{Introdução}

O termo devastação, em francês ravage, foi utilizado por Lacan para caracterizar a alternância entre amor e ódio na relação entre mãe e filha. Entretanto, neste trabalho, tentaremos ampliar seu sentido na tentativa de pensar também sua incidência no masculino.

O desamparo consiste no drama humano por excelência, dado que nascemos num estado de total dependência em relação ao outro que, nos reconhecendo enquanto semelhantes, deve propiciar as condições de sobrevivência, desde as mais primárias tais como a fome e a sede, até a de ser desejado, amado e reconhecido. O lugar de referência creditado ao outro favorece que ele seja tomado como "grande Outro" - com O maiúsculo —, como designou Lacan, lugar de inscrição do sujeito humano no campo da linguagem, já que, enquanto seres falantes e falados, tudo o que diz respeito à nossa sobrevivência passa pela linguagem. A questão que surge no início da vida e que se torna central para todo ser humano é a de saber que lugar ele ocupa no desejo do Outro, um enigma impossível de ser decifrado, já que o que pode ser dito não abarca a vastidão do dizer. As palavras estão sempre à meia medida do que se pode dizer. Tal realidade concerne a todo ser humano, entretanto, pode-se dizer que é numa identificação ao feminino nas mulheres que a relação ao Outro ganha matizes singulares. A dificuldade em se localizar no desejo do Outro, de sentirem-se merecedoras de seu amor, talvez seja o desafio que muitas mulheres vivenciam no contexto de suas relações (Freud, 1895/2006g; Zalcberg, 2007).

Deixar de ser amada, ser abandonada, é o maior medo das mulheres, em razão de que, para elas, ser amada é uma necessidade maior do que amar. O amor é o que dá "consistência" a seu ser, daí ser comum afirmar que o que elas amam é o amor. O amor se coloca como uma moeda valiosa nas trocas amorosas. Algumas, 


\section{LITERATURA, ARTE, CULTURA}

inclusive, são capazes de renunciar a tudo para se manterem numa posição de entrega em relação ao Outro, e isso pode ser tanto para o melhor, quanto para o pior, tendo em vista que a parceria amorosa pode culminar em devastação. No entanto, esse fenômeno não é uma experiência vivida apenas por elas, dado que os homens de certo modo também a experimentam.

É preciso esclarecer que a psicanálise, campo que nos orienta na escrita deste trabalho, subverte a lógica que vigora em torno da noção de gênero ao indicar a inexistência de uma correspondência exclusiva entre a anatomia do homem ou da mulher - e o que ela designa como masculino e feminino. Da mesma forma, o que Freud referiu metaforicamente como ativo e passivo não corresponde respectivamente ao que diz respeito ao homem ou à mulher, já que homens e mulheres podem ser tanto ativos quanto passivos. A hipótese freudiana da bissexualidade psíquica indica que o sujeito pode ocupar diferentes posições na fruição da satisfação pulsional. Porém, na visão de Lacan, para além de uma dualidade de sexos, há em nós uma dualidade de gozos: o gozo fálico, relativo à posição masculina, e o gozo Outro, relativo à posição feminina.

A hipótese que desenvolvemos neste trabalho relaciona-se à devastação no masculino, um tema que acreditamos ser pouco explorado e que, a nosso ver, pode contribuir para um maior esclarecimento acerca da violência contra a mulher, o que aqui destacamos ser, na verdade, a violência contra o feminino na mulher. Ou seja, contra uma potência de entrega que pode ganhar dimensões avassaladoras para aquele que se vê tomado por uma experiência de dessubjetivação, reagindo violentamente, sobretudo, frente ao indicativo de impossibilidade de alguma restituição fálica.

Esse é, certamente, um fenômeno que se repete na memória cultural das sociedades. Por mais que façamos referências às mulheres e aos homens no sentido empírico, nossa proposta não é a de pensar sobre a violência de gênero, mas sobre a violência que incide sobre o feminino, violência que se volta sobretudo àquilo que pode portar ou aludir às insígnias do feminino. Daí, não apenas as mulheres, mas também travestis, gays, e todos aqueles que remetem a um modo de satisfação Outro que, escapando à lógica fálica, fazem supor um gozo Outro, devem ser penalizados pela ameaça que representam. Para tanto, privilegiaremos a teoria lacaniana acerca da hipótese da existência de uma dualidade de gozos: o fálico e Outro, que escapa à lógica fálica.

Devemos esclarecer também que, para fundamentar a hipótese que sustentamos, vamos evocar uma distinção que não está clara no seminário Encore, de Lacan, entre gozo Outro e gozo do Outro. Entendemos o gozo do Outro como relacionado à vivência de um gozo intrusivo e devastador 
atribuído ao Outro, vivido como absoluto, tal como ocorre nas psicoses. Resta nele a aniquilação do sujeito. Essa abordagem será fundamental para pensarmos, possivelmente, uma das dimensões do que talvez se passe na devastação no masculino, bem como nas consequências dessa experiência de invasão, que podem, muitas vezes, desencadear diversas formas de violência contra o feminino na mulher, chegando até mesmo à ocorrência do feminicídio.

\section{Gozo fálico e gozo Outro}

No início de seu ensino, Lacan conceitualiza o gozo em sua universalidade; contudo, no seminário Mais, ainda (1972-73/2008c) diferencia duas lógicas distintas de gozo: a do gozo fálico e a do gozo Outro, esse último sublinhado, aqui, como gozo feminino. Com isso, inaugura uma nova maneira de abordar uma problemática que vai além da relacionada com a diferença sexual, que até hoje evoca discussões acaloradas, principalmente nos meios psicanalítico e filosófico. É possível perceber que o grande esforço de Lacan consistiu em abordar a diferença sexual enquanto não absolutamente submetida à anatomia, indo além da teoria freudiana da bissexualidade, abordando de uma maneira mais complexa o que se coloca no par atividade -passividade, avançando sobre a questão das posições subjetivas assumidas pelo sujeito frente ao gozo. Essas questões serão contempladas especialmente com o conceito de sexuação, que abordaremos mais adiante.

Lacan (1972-73/2008c) explicita que o gozo fálico, mesmo estando implicado naquilo que o sujeito experimenta como sexual, via as fantasias que o sustentam, está longe de se restringir ao gozo relativo ao órgão. Em razão de ser ancorado pelo inconsciente, esse gozo é situado por Lacan no campo da linguagem, encontrando-se fora do corpo, mas mantém uma relação de dependência com ele. O gozo fálico é o gozo do sentido ofertado pela palavra, que reveste o corpo, conferindo-lhe diversas significações. Tal gozo comparece quando o sujeito é capaz de se apropriar dos significantes que fazem parte de sua história, utilizando-os como via de afirmação da vida e de si mesmo. O fato de falar, a apropriação da linguagem, implica um modo de fruição fálica. Esse gozo diz respeito à forma como cada sujeito se relaciona com o seu sexo, se vincula à possibilidade de se apropriar de diferentes maneiras do significante fálico, enquanto elemento diferencial indispensável para a constituição subjetiva. 


\section{LITERATURA, ARTE, CULTURA}

O fato de um sujeito falar, apropriar-se da linguagem e, portanto, incluir-se no jogo da diferença, já denota uma inscrição fálica. Entretanto, o modo como cada sujeito opera a partir dessa inscrição, ou do que faltou a ela, trará consequências quanto às suas possibilidades de responder às exigências da vida quer no plano sexual, amoroso, profissional, familiar etc. $\mathrm{O}$ acesso ao gozo fálico depende da forma própria de um sujeito valer-se do significante Nome-do-Pai, em suas diferentes versões, o que faculta ao sujeito um ancoramento frente ao deslizamento da rede de significantes que compõem o campo da linguagem, como um meio de se referendar nesse campo, dando um basta a esse deslizamento e podendo incluir-se, por via de uma nomeação que represente o sujeito frente a outros significantes, nesse universo simbólico da linguagem.

Pode-se perceber o quanto o acesso ao gozo fálico é fundamental ao ser falante, dado que é condição mesma de sua existência. Porém, a grande questão é que algo na nossa existência ex-siste, evidenciando um "fora do campo da linguagem", embora só por ela possa ser referendado. Assim, atento aos desdobramentos da teoria freudiana acerca da sexualidade feminina, bem como ao campo de pesquisa aberto pela descoberta por Freud de satisfações que se situam "além do princípio de prazer", Lacan (1972-73/2008c, p. 80) elabora a hipótese da existência de um gozo Outro que se situa "mais além" da lógica fálica, um gozo que ele designa como feminino, suplementar ao gozo fálico, como afirma: "Que tudo gira em torno do gozo fálico, é precisamente o de que dá testemunho a experiência analítica, e testemunho de que a mulher se define por uma posição que apontei com o não todo no que se refere ao gozo fálico" (p. 14).

Pelo visto, há aí a indicação de que, "mais além do princípio de prazer", podemos vislumbrar uma lógica outra de satisfação paradoxal, que, "remetida" ao campo do ser, revela a impossibilidade de qualquer totalização, revelando que há algo Outro, algo "de fora" que atravessa nossa existência, indicando que existir como humano é, também, de certo modo, ex-sistir (para usar o neologismo lacaniano). O enigmático aforisma "A mulher não existe" é criado por esse autor como um modo de dizer que as mulheres não estão totalmente referidas ao feminino porque participam também do registro fálico, o que, a nosso ver, pode ser melhor entendido com a observação de que os sujeitos falantes, sejam homens, mulheres, passíveis das autodesignações que forem, não são abarcados pelo registro fálico de forma absoluta. Isso porque o campo da linguagem não é absoluto, sempre algo o fura. Algo falta a esse Outro indicando a ex-sistência, revelando que há uma dimensão 
que escapa ao que pode ser apreendido pela linguagem em sua lógica fálica, sexual, seccionada de funcionamento. Algo resta hors-sexe, fora do registro sexual, indicando o que há mais além do princípio de prazer, no qual não vigora a descontinuidade. Que as mulheres, em sua dimensão empírica, sejam lembradas como o que evidencia que o registro fálico não é todo, é um bom indicativo de uma correlação do feminino com um Outro modo de operar como o gozo. A construção do conceito de LA por esse autor mostra o lugar de alteridade radical que o feminino ocupa. $\mathrm{O}$ artigo definido $\mathrm{A}$, designativo dA mulher, tem que ser barrado, já que não haveria generalização possível dA mulher - essas têm que ser contadas uma a uma. Disso decorre o fato de a mulher ser vista como um enigma, um "buraco radical, que se situa num plano Outro". Um outro nome para o real, ou para o que se situa além do princípio de prazer (Maurano, 2011, p. 57).

Contudo, o fato de Lacan afirmar que "A mulher não existe" não significa que não existam as mulheres empíricas, mas sim que não há uma representação da mulher no inconsciente, o que é o mesmo que afirmar que as mulheres devem ser tomadas uma a uma, ou seja, cada mulher deve ser abordada a partir do que ela tem de singular. Não há, portanto, um significante 754 que defina A mulher.

As mulheres, por estarem referidas não só à castração, mas sobretudo à privação, pelo fato de que, para elas, a falta se presentifica em algo de sua experiência real, são suscetíveis à vivência do que excede ao campo simbólico, e que se relaciona com o furo, com o vazio, com a presença da heteridade em relação ao falo. Apesar de participarem da função fálica da castração, as mulheres não estão de todo submetidas a essa função (Maurano e Souza, 2017).

Se é a relação ao falo que estabelece a distinção sexual, resta, numa mulher, uma parte que não está submetida ao sexual e que, por isso, faz apelo a outra coisa: ao ilimitado, ao inacessível, ao invisível, em último caso, ao amor, que é o milagre que vem no lugar da impossibilidade de o sexo conjugar tudo, ou de a insuficiência da relação fálica delinear o que interessa da existência (Maurano, 2006, p. 51). Dito de outro modo, o osso da impossibilidade da relação sexual no sentido da complementaridade que falta entre os sexos, indicando a dimensão real do que não para de não se escrever, consegue, na contingência do instante fulgurante do "milagre do amor", parar de não se escrever. E é por isso mesmo que o passo seguinte é o que vai na direção de transformar esse contingente em necessário, via por onde essa experiência se impõe como o que não para de se escrever, mais e mais ainda. 


\section{LITERATURA, ARTE, CULTURA}

Modo de se tentar elidir o osso do real. A visada de um gozo não marcado pela diferença fálica se impõe pela própria insuficiência do gozo fálico.

Tal gozo, pelo fato de ser Outro em relação ao falo, é designado por Lacan (1972-73/2008c) como gozo feminino, um gozo a mais que se supõe existir, mas que, no entanto, é impossível de ser expresso por meio das palavras: "desse gozo, a mulher nada sabe, é que há tempos que lhes suplicamos, que lhes suplicamos de joelhos - eu falava da última vez das psicanalistas mulheres - que tentem nos dizer, pois bem, nem uma palavra [...] Esse gozo que se experimenta e do qual não se sabe nada, não é ele o que nos coloca na via da ex-sistência?" (p. 80).

Esse gozo sobre o qual nada se sabe, em razão de se situar fora do campo representativo que é comandado pelas leis da linguagem, parece evocar algo da relação do sujeito com o real, com o ex-nihilo, com um momento mítico originário onde não há sujeito ainda, onde nada existe, o que o situa tanto aquém, quanto além do princípio de prazer, como supõe Lacan: "Essa articulação se faz naquilo que resulta da linguagem o que quer que façamos, isto é, um suposto aquém e um além. Supor um aquém — bem sentimos que só há nisso uma referência intuitiva" (p. 50). Essa suposição de um aquém da linguagem, ainda que de caráter mítico e intuitivo, pode nos servir para iluminar algumas ideias.

Bem sabemos que as experiências de êxtase que os místicos testemunham através de seus poemas oferecem elementos para que Lacan suponha a existência de um gozo Outro: "eles entreveem, eles experimentam a ideia de que deve haver um gozo que esteja mais além [...] Essas jaculações místicas, não é lorota nem só falação, é em suma o que se pode ver de melhor...” (p. 82).

O que caracteriza o gozo relativo à experiência mística é a atitude de entrega total a Deus, que é identificado ao Outro absoluto, lugar da verdade. Na busca por uma maior comunhão com o divino, os místicos se entregam ativamente às orações e meditações, até ao ponto de se destituir de sua própria subjetividade. No artigo "Lacan e a experiência mística à luz da psicanálise", Maurano e Albuquerque (2019) destacam que a experiência mística se aproxima do que Lacan apontou como sendo a principal característica do gozo Outro, que é a entrega de si. Embora o êxtase místico não se confunda exatamente com o que Lacan indica como gozo Outro, tanto um quanto o outro têm como condição de possibilidade um tanto de dessubjetivação. Tal experiência de dessubjetivação é, paradoxalmente, buscada de maneira ativa nos relatos dos místicos.

Como considera Pommier (2014) em Féminin, révolution sans fin, o gozo místico não se confunde com a loucura, com ataques epiléticos ou 
mesmo com um quadro de histeria, mas resulta de um trabalho insistente de pregações, orações e privações que culmina na união mental com o divino. No caso das mulheres, essa união é preparada durante dias, meses e anos, até o momento em que elas se tornam esposas de Cristo, e podem gozar ativamente dessa união. É uma experiência solitária, que só chega ao conhecimento devido aos relatos feitos aos padres e monges, que os escreviam. Desse modo, se tornaram testemunhas dessa união. É interessante o fato apontado por Pommier de que todas as místicas se tornavam participantes dos mesmos sofrimentos relacionados à cruz de Cristo, como se experimentassem uma espécie de mimetismo no qual suas feridas e todo sofrimento do calvário fosse revivido por elas. No entanto, a vivência dessa experiência é permeada por um júbilo, uma felicidade extrema, "A felicidade de gozar eternamente de sua presença", como sublinha Pommier, citando Santa Tereza (p. 20). Como se no "des-ser" de si pudesse fazer a experiência do Ser divino ser fora de si.

É interessante notar que a destituição subjetiva inerente à experiência mística é buscada ativamente, não sendo, portanto, da ordem de uma invasão, como se Deus - o Outro radical - possuísse a pessoa sem seu consentimento. Pommier chega a afirmar que, na verdade, são os místicos que possuem a Deus (p. 19).

A dessubjetivação consentida, ou seja, a busca ativa pela passividade na relação com Outro, também é uma característica suposta ao gozo Outro feminino, podendo ser este o verdadeiro e enigmático dark continent, o continente negro habitado pelas mulheres, sobre o qual Freud se refere no texto "A questão da análise leiga" (1926). Trata-se, no gozo Outro, de uma entrega na qual o sujeito, abstraído de sua própria subjetividade, coloca-se em continuidade com o Outro, daí sua vinculação com "mais além do princípio de prazer", imerso num gozo mais além, tomado por uma satisfação paradoxal que se situa fora do campo sexual, "incidindo sobre o ponto onde o sexual rateia, não se revelando suficiente para sustentar a relação do humano com a amplitude da existência ou com o imperativo da satisfação" (Maurano, 2011, p. 59).

Esse estranho gozo não submetido ao sexual, relacionado especialmente sobre o que aqui tentamos designar como feminino na mulher, mas que pode também incidir sobre o feminino no homem, é desconhecido pelo sujeito que nada sabe acerca dele. Não se trata de uma experiência orientada pelo sujeito, mas uma experiência pela qual o sujeito é atravessado mesmo a despeito de si mesmo. Aliás, aqui vale novamente mencionarmos sua similaridade com a experiência do êxtase místico, a qual, como instrui São João da Cruz, "para se 


\section{LITERATURA, ARTE, CULTURA}

chegar pois a ela, há que antes pôr-se em trevas, do que abrir os olhos para a luz" (Cruz, 1578/1960, p.90).

Para avançarmos nas reflexões aqui propostas, devemos sublinhar que esse gozo dito feminino, gozo que se encontra em posição de alteridade em relação à norma fálica e à fruição dela advinda, reserva ainda outras complexidades, como a que tentamos depreender de uma possível diferença entre gozo Outro e gozo do Outro, que não está clara no Seminário 20 de Lacan, mas que supomos ser fundamental para o encaminhamento do que estamos propondo acerca da temática da devastação. Essa diferença, apontada anteriormente por Maurano e Albuquerque (2019), tem por base a diferenciação indicada por Lacan entre Schreber e São João da Cruz, no seminário $A s$ psicoses.

\section{Gozo do Outro e gozo Outro}

No capítulo "O fenômeno psicótico e seu mecanismo", do seminário 3, As psicoses, Lacan (1955-56/1988) retoma a análise estabelecida por Freud (1911/2006c) no texto "Memórias de um doente dos nervos", conhecida como "o caso Schreber". O autor das "memórias" é Paul Schreber, um juiz que desencadeia um surto psicótico ao ser nomeado presidente da Suprema Corte alemã. O surto do presidente Schreber e os delírios que ele cria na tentativa de reconstruir minimamente seu mundo mostram os modos como o Outro comparece nas psicoses. O Outro (com "O" maiúsculo) designa o campo da linguagem. Para se constituir como ser falante, o sujeito se aliena aos significantes que lhe vêm do Outro, afinal, a linguagem, a recebemos do Outro. No entanto, existem diferenças no lugar ocupado pelo Outro na neurose e nas psicoses. Na neurose, a inscrição da lei simbólica do Pai, modo pelo qual Lacan propõe indicar a adesão feita por nós ao mundo simbólico, insere o sujeito na ordem da castração, do limite, fazendo com que o Outro seja tomado como insuficiente, barrado, e é essa insuficiência que dá espaço para que o sujeito advenha como desejante, respondendo com seu desejo à falta. Nas psicoses, entretanto, a falha na inscrição simbólica traz para a cena a experiência de confrontação com o Outro sem falhas, onipotente, que não deixa nenhum espaço para o sujeito se constituir como desejante, arriscando fixá-lo enquanto objeto de uso e abuso desse Outro que incide como absoluto. Por isso, nas psicoses o Outro comparece como absoluto, como portador de um gozo invasivo e avassalador, tal como na experiência de Schreber. 
Freud sublinha que logo após receber a notícia de sua nomeação, um pensamento ocorre a Schreber entre o sono e a vigília: que "seria belo ser uma mulher e submeter-se ao ato da cópula" (Freud, 1911/2006c, p. 24). Depois da nomeação, surge a experiência bizarra que lhe cobrava ser transformado em uma mulher, fazendo com que Schreber acreditasse que uma instância que ele denomina "a Ordem das Coisas" exigia de modo imperativo sua "emasculação", e que nenhum outro caminho era possível senão o de que ele se reconciliasse "com o pensamento de ser transformado em mulher" (Schreber, 1903/2006, p. 31).

$\mathrm{Na}$ impossibilidade de responder a partir da função fálica agenciada pela inscrição da Lei simbólica, que lhe possibilitaria barrar a invasão dessa Outra ordem absoluta, Schreber se vê avassalado por toda sorte de delírios e alucinações relacionados à emasculação, o que Lacan designou como empuxo-à-mulher. O empuxo-à-mulher indica que, ao ser assombrado pelo delírio de emasculação, o sujeito psicótico mostra que na falta da inscrição da castração simbólica, no campo onde falta significante para dizer o sexo, ele se situa totalmente do lado da privação, ou seja, ele se enxerga como totalmente desprovido da referência imaginária sustentada pelo órgão sexual ou pelo que quer que seja que represente uma potência de distinção. Aspirado por uma não delimitação, a solução encontrada por Schreber diante dessa invasão avassaladora foi a de criar um delírio no qual ele torna honroso "tornar-se a mulher de Deus e redimir a humanidade", via por onde ele encontra meios de falicização e, portanto, um lugar para chamar de seu (Freud, 1911/2006c, p. 25).

Tal experiência intrusiva relatada por Schreber não é nada rara. O que revela é que, nas psicoses, o gozo do Outro, tomado como absoluto, provoca a aniquilação subjetiva, dado que ele comparece de modo devastador. Isso marca a diferença entre essa invasão aniquilante e a entrega consentida e até mesmo buscada, do lado dos místicos, como referimos acima.

Enquanto Schreber é anulado subjetivamente pelo Outro, comparecendo na sua escrita como objeto de um gozo avassalador, São João da Cruz, ao relatar seu movimento espontâneo em direção ao divino, transforma-se num poeta, como sublinha Lacan (1955-56/1988): “a poesia faz com que não possamos duvidar da autenticidade da experiência de San Juan de la Cruz... A poesia é criação de um sujeito assumindo uma nova ordem de relação simbólica com o mundo. Não há absolutamente nada disso nas Memórias de Schreber" (p. 69).

É por essa via que nos parece fecundo sublinhar a distinção entre o gozo da entrega consentida — gozo Outro - relativo à experiência de 


\section{LITERATURA, ARTE, CULTURA}

dessubjetivação, que é o que se verifica em São João da Cruz, enquanto, do lado de Schreber, o que há é uma experiência de aniquilamento da subjetividade, operado pela invasão do gozo do Outro que o reduz a um objeto decaído.

É importante lembrar que tanto o gozo Outro como o gozo do Outro são suposições lógicas que visam, de certo modo, tentar construir um dizer sobre determinados fenômenos que são da ordem do real, ou seja, do que não faz sentido algum. Pensamos também que a experiência do gozo Outro só é possível a partir do enodamento dos registros — Real, Simbólico e Imaginário —, que é o que possibilita a mediação simbólica, e a retomada da posição fálica, que é o que nos faz supor que a escrita testemunhal dos místicos, com seus poemas, escritos após a experiência, testemunham um gozo que se avizinha ao que Lacan hipotetizou como gozo feminino ou gozo Outro.

É interessante notar que o psicanalista Néstor Braunstein (2007), no livro Gozo, sustenta a hipótese da existência de três gozos: o gozo do Ser, o gozo fálico e o gozo Outro. Braunstein encontra no seminário XIV - A lógica da fantasia uma citação onde Lacan faz uma correspondência entre o gozo do ser e gozo do Outro, indicando sua localização "na intersecção entre o imaginário e o real sem mediação simbólica" (p. 132).

Esse autor entende que o gozo do Ser corresponde ao gozo que incide em certas formas da psicose. Ao gozo do Ser, referido também como mítico, aquém da castração e perdido por ela, se atribui a condição de ser gozo do Outro, embora em outra passagem, entendendo o gozo do Outro como gozo do Outro feminino, emergindo mais além da castração - e embora fora da linguagem, efeito de passagem por ela - , ele o tenha oposto ao gozo do Ser, remetido à experiência psicótica (pp. 61 e 83). Subvertendo um tanto a proposta de Braunstein, e tomando em consideração uma necessária distinção quanto a diferentes incidências do feminino para um sujeito, propomos pensar que a suposição lacaniana da inexistência $\mathrm{d} A$ Mulher outorga ao feminino uma posição um tanto quanto mítica e, se a referimos à anterioridade relativa à própria divisão sexual, o hipotético ou mesmo mítico gozo feminino hors-sexe pode também ser correlacionado ao gozo do Ser, podendo trazer, no entanto, efeitos de duas ordens bastante diferenciadas. Uma, na qual se evidencia como gozo do Outro, gozo invasivo, denotado pela experiência psicótica denominada como empuxo-à-mulher, mas certamente pode haver outras experiências nas quais o Outro comparece como Absoluto, intrusivo, não barrado $(\mathrm{S}(\mathrm{A})$ ), produzindo uma angústia relativa à intrusão do real no imaginário, aquém de qualquer contorno simbólico. Tal experiência traz 
como efeito o horror da aniquilação subjetiva, trazendo consequências tão devastadoras quanto as defesas para fazer face a elas. Nesse espectro talvez se incluam algumas das experiências nas quais o empuxo-à-mulher desperte uma injúria fálica de proporções avassaladoras tanto para o próprio sujeito quanto para seu entorno. A outra ordem da experiência a que propomos diferenciar como gozo Outro, embora se situe além da representação, e até por estar além da castração, não prescindiu totalmente de ter se servido dela. Nessa dimensão, o Outro relativo a essa vivência comparece como $S(\mathbb{A})$, ou seja, guarda em si uma falta que acena com alguma possibilidade operativa e mesmo jubilatória, como é suposto se dar com o gozo a mais feminino e com o gozo místico, com o qual tem parentesco.

$\mathrm{Na}$ dimensão feminina do gozo Outro, este é aludido como gozo não complementar, mas suplementar à insuficiência do gozo fálico para abarcar as perspectivas de gozo na ex-sistência, ou seja, na dimensão em que nossa existência ultrapassa o que pode ser demarcado pelo sistema representacional, afeita ao campo do Outro como campo da linguagem. O Outro feminino é o que marca que o Outro da linguagem não consegue dizer tudo. Ele é o que barra o Outro da linguagem, o que Lacan sugere notar como A, via por onde o feminino indica uma barra, um furo e, ao mesmo tempo, em que comparece indicando a possibilidade de suplência a isso, pela via da ex-sistência de um gozo mais além do fálico.

Outra reflexão que pode também nos ajudar é pensar que, se o gozo do Outro é marcado pela intrusão do Real no campo do imaginário, sem a mediação simbólica, o gozo Outro talvez possa ser pensado como uma operação na qual o Imaginário se impõe sobre o Real, e, embora prescinda da mediação simbólica, só o faz porque pode ter se servido dela. Qual tipo de experiência pode revelar a incidência desse modo de gozo, é uma vasta discussão, mas, certamente, cremos poder cernir, dentre elas, o que tange ao processo que preside a invenção, a criação. Mas essa é uma outra questão.

Acreditamos que tal distinção pode servir para a compreensão do fenômeno da devastação, dado que, no que concerne ao gozo do Outro, a ausência da anuência do sujeito faz com que essa experiência seja vivida como uma invasão que desencadeia uma angústia avassaladora. É possível que esse fenômeno possa ser relacionado ao sentimento da inquietante estranheza a que Freud (1919/2019) se refere no ensaio Das Unheimlich. A possível relação entre o gozo do Outro e o fenômeno da inquietante estranheza, quando experimentada de forma radical, abre caminhos para pensar que a devastação promovida pelo gozo do Outro não se limita à experiência 


\section{LITERATURA, ARTE, CULTURA}

da psicose. É possível que outros fenômenos clínicos, e mesmo culturais, onde o Real se imponha sem mediação simbólico-imaginária, revelando-se como alteridade todo-poderosa, provocando a irrupção da angústia, apontem também, em alguma dimensão, para essa experiência intrusiva do gozo do Outro (Maurano e Souza, 2017).

Levando em consideração o que foi exposto, para efeito do tema tratado neste trabalho acerca da violência contra o feminino na mulher - violência essa imposta cultural e subjetivamente, sobretudo por homens —, formulamos a hipótese de que a devastação pontual provocada pelo gozo do Outro é um fenômeno que pode ser também vivido por sujeitos posicionados do lado do masculino, que, por se "garantirem" na posse imaginária do falo, quando deslocados dessa possibilidade identificatória, tomados pela angústia, podem se ver avassalados pelo horror à emasculação, ou seja, remetidos ao empuxo-ao-feminino. Por essa perspectiva, nos cabe interrogar: não seria a violência contra a mulher a expressão de uma defesa radical frente ao feminino? Não estaria aí senão pelo menos uma das motivações para tanta violência dirigida às mulheres no decorrer da história, produzindo através dos tempos uma memória sangrenta desse fenômeno?

No intuito de tentar construir uma explicação estrutural para isso, vamos nos valer da tábua da sexuação construída por Lacan com o objetivo de situar a particularidade das posições subjetivas masculina e feminina na fruição do gozo, o que acreditamos que vá nos ajudar a destrinchar essas questões.

\section{As fórmulas da sexuação}

A insuficiência do gozo produzido pelo balizamento fálico para abranger tudo que concerne ao campo paradoxal de satisfações que um sujeito pode obter, abre caminho para a construção de uma suposição lógica acerca da existência de um gozo Outro situado para além do princípio de prazer. O gozo feminino é, portanto, uma suposição lógica construída a partir do campo de pesquisa inaugurado pela perspectiva do além do princípio de prazer, contemplado, não à toa, pela complexidade da pulsão de morte. A lógica possibilita a construção de uma escrita matemática que formaliza o que Lacan propõe como sendo uma lógica dos gozos, presentificada pelas fórmulas quânticas da sexuação. A invenção da "lógica dos gozos" torna possível falar sobre o que se situa além do campo das representações, ou seja, o que está fora da linguagem (Lacan, 1972-73/2008c). 
As fórmulas da sexuação foram esboçadas por Lacan no seminário "Ou pior..." e no escrito "O aturdito", mas é no seminário XX - Mais, ainda... que sua forma definitiva será apresentada. O mito do Pai da Horda, referido por Freud (1913) no texto "Totem e Tabu", será utilizado por Lacan para mostrar que a condição do todo é a exceção, ou seja, na sexuação dos sujeitos, aquele que pode tudo, que não tem limites, que não tem divisão, só pode ser situado miticamente, e fica de fora das trocas humanas. Para estruturar seu pensamento acerca da grande questão das diferenças, Lacan propõe, na tábua da sexuação, uma secção, uma divisão, um lado HOMEM e um lado MULHER, para evidenciar as posições subjetivas assumidas pelo sujeito frente ao gozo. Desde já é interessante pensarmos que o sujeito que se coloca do lado homem, marcado por essa posição, não precisa ser necessariamente um homem; pode ser um sujeito mulher que se experimenta subjetivamente enquanto homem e vice-versa. Afinal, como já observava Freud, todos nós somos, em certa medida, bissexuais.

É relevante observar que, nesse primeiro nível da tábua, as designações Homem e Mulher servem para indicar posições subjetivas, semblantes, tal como aquelas que encontramos nos pronomes via os quais nos designamos. Reproduzimos abaixo a tábua da sexuação construída por Lacan, e em seguida 762 elaboramos uma breve explicação acerca dos matemas.

\section{HOMEM MULHER}

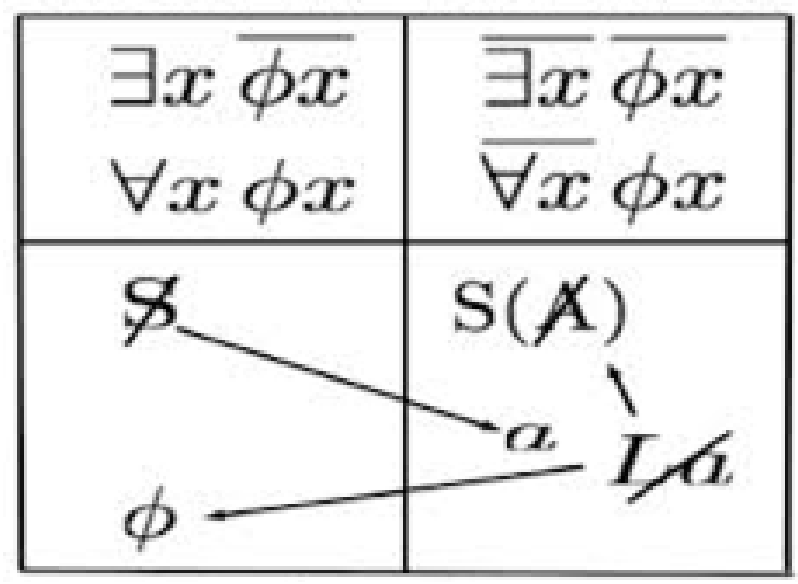

Figura 1 - Tábua da sexuação apresentada no seminário Mais, ainda... (1972-73) 


\section{LITERATURA, ARTE, CULTURA}

No segundo nível da tábua, temos indicadas as modalidades de gozo decorrentes dessas diferentes posições. No masculino, a generalização do gozo fálico, regra que vale para todo masculino, se baseia, como toda regra, numa exceção. A fórmula $\exists x x^{1} x^{1}$ indica a existência dessa exceção que funda o conjunto dos homens, ou seja, que existe pelo menos um que não é castrado, que é todo fálico. Eis aí uma referência ao Pai da Horda de "Totem e tabu" (Freud, 1913/2006d), um mito acerca de um pai que gozava de todas as mulheres até que, "um dia, os filhos expulsos da horda pelo pai que gozava de todas as mulheres regressaram, mataram-no e devoraram seu cadáver, pondo fim à existência daquela forma arbitrária de poder" (p. 145). No entanto, a morte do pai instituiu o tabu do incesto, como o desejo proibido que impede que os filhos gozem das mulheres do pai. Assim, uma vez morto, excluído, sustenta a lei que instaura para todos, homens e mulheres, o funcionamento do limite da castração como valendo para todos, ou seja, todos se situam do lado da lei que interdita o incesto - é o que mostra a fórmula Vx $\Phi x .^{2}$

Disso resulta, do lado homem, como mostra o terceiro nível da tábua, as formas da fantasia, o sujeito enquanto dividido ( $($ ) e o falo $(\Phi)$ enquanto referência prevalente do masculino. O gozo fálico que lhe é correlativo é balizado pela fantasia, que compõe a relação do sujeito dividido ( $($ ) endereçado ao objeto amalgamático de seu desejo como o que é buscado na mulher, do outro lado da linha de corte da tábua. O gozo fálico masculino é sinalizado pelo vetor que vai de $S$ e que ultrapassa a linha de corte em direção ao objeto da fantasia inconsciente $(S \rightarrow$ a), situado do lado feminino (Lacan, 1972-73/ 2008c, pp. 85-86).

Tal perspectiva indica que, na fantasia viril, se goza tomando a mulher como objeto de fruição. $\mathrm{O}$ endereçamento ao feminino, identificado ao objeto (a), coloca em vista a possibilidade de haver um controle sobre ele. Podemos supor que a fantasia masculina de dominação do objeto, via pela qual o sujeito posicionado do lado homem pretende encontrar como retorno a própria confirmação de sua identificação viril, encontrou, ao longo da história, tanto versões românticas de entregas consentidas quanto nefastas, de submetimento cruel. A objetificação das mulheres pelo olhar masculino na memória das sociedades talvez decorra da exacerbação dessa fantasia, explorada pelo machismo

${ }^{1}$ Existe ao menos um $\mathrm{x}$ tal que a função fálica não se aplica ao x. "O um que existe é o sujeito suposto de que aí a função fálica não compareça” (Lacan, 1973/2003, p. 459).

${ }^{2}$ Para todo $\mathrm{x}$ é verdadeiro que a função fálica se aplica ao $\mathrm{x}$. 
estrutural, que consideramos ser uma forma de construção de uma masculinidade que favorece o repúdio ao feminino.

A despeito de todas as conquistas obtidas pelas mulheres no campo social, que lhes permitiram ocupar o lugar de cidadãs, deixando de serem consideradas propriedades - primeiro, do pai, e depois, do marido - e que lhes garantiu, sobretudo no Ocidente, o direito de fazer escolhas no campo amoroso, sexual, profissional etc., versões exorbitantes desse modo de afirmação da virilidade ainda estão presentes na grande maioria das sociedades. Não podemos negar aos sujeitos masculinos seu modo próprio de gozar e de afirmar, porém, o problema é quando isso exorbita, sem a adesão consentida feminina.

Por outro lado, já no seminário 11 , Os quatro conceitos fundamentais da psicanálise, Lacan (1964/2008b) esclarece que as mulheres, pelo fato de também estarem inscritas na função fálica, não se identificam totalmente com a posição de objeto, entretanto, podem encarnar imaginariamente esse lugar na fantasia dos homens para obter deles o almejado falo. É no campo do discurso amoroso que ela consente em ser o objeto $a$, causa de desejo para o homem. É no discurso amoroso, que delimita o que, em sua evanescência, 764 ela é para ele, como objeto a, que ela busca seu gozo por intermédio da fala de amor, das palavras ao pé do ouvido fálico, ela deseja ser amada e desejada pelo que ela não é, o falo. Enquanto sintoma do homem, ela se oferece como seu meio de gozo. Vê-se aí toda a função da mascarada no jogo feminino que faz semblante, que faz de conta que se é o que não se é. Daí a beleza, para as mulheres, servir como armadilha para capturar o desejo.

O gozo fálico comporta um limite imposto pela castração simbólica que faz com que ele se afigure como insuficiente, daí ser necessário buscá-lo mais e mais, como demonstra Don Juan, ${ }^{3}$ personagem arquetípico da literatura espanhola que se tornou o símbolo do homem sedutor que está sempre à caça de novos amores. É nessa perspectiva que o objeto comparece enquanto causa e enquanto o que causa, colocando em movimento, fazendo prosperar

${ }^{3}$ Rosa Maria de Siqueira, pesquisadora portuguesa do donjuanismo, no texto "A migração de um motivo: o mito de Don Juan e as pulsões do feminino" (2016) detalha que $O$ burlador de Sevilha, de Tirso de Molina, inaugura na literatura a longa saga do donjuanismo. Contudo, antes dessa grande obra, em 1581 já havia surgido uma peça representada em Sevilha sob o título "El infamador", de autoria de Juan de la Cueva. 


\section{LITERATURA, ARTE, CULTURA}

o circuito pulsional para além da "petite mort", maneira como os franceses designam o gozo sexual. A estratégia defensiva de Don Juan era a de se valer de conquistas amorosas para retomar, a cada novo encontro, a posição viril. Com o passar do tempo, esse personagem acabou se tornando um símbolo do homem sedutor que está sempre à caça de novos relacionamentos.

$\mathrm{Na}$ vida cotidiana, não é incomum nos depararmos com homens que, para manter a imagem viril, estão sempre à procura de mulheres para "comer", o que nos faz pensar num modo de incorporação que vigora nos primórdios dos processos de identificação, no qual o eu busca introjetar o que é bom, para construir um si mesmo. Tais homens estão sempre "pegando todas", indicando, com isso, certo modo de construção da masculinidade sustentada pela crença de que homem que é homem "não nega fogo". $\mathrm{O}$ apelo incessante ao gozo fálico como legitimação do que se acredita ser um homem viril, um "macho", também está presente nos casos em que a violência é recorrente nas relações amorosas, dado que um homem não é violento apenas com uma mulher. Daí ser possível supor que a referência ao pelo menos um que não é castrado pode funcionar como um apelo imaginário que impele o sujeito a vislumbrar a possibilidade de criar estratégias que possibilitam suprimir a castração, atuando no sentido de que o interdito da castração possa ser suspenso, sem atinar para o fato de que, na verdade, o proibido vela o impossível do gozo pleno.

No lado mulher da tábua da sexuação, Lacan mostra a privação radical reveladora de que não há mulher que não esteja submetida à função fálica da castração. Porém, a lei da castração não abarca a totalidade da mulher, mas sim incide apenas parcialmente sobre ela.

Não existe uma mulher que esteja totalmente do lado feminino, dado que a apropriação da linguagem já fala de uma inscrição no domínio fálico, derivando daí o aforismo "A mulher não existe", porque não existe ninguém que seja totalmente mulher, sem referência alguma ao que é regido pela atividade fálica. Isso é o que Lacan representa com a fórmula $\mathrm{x} \Phi \mathrm{x} .{ }^{4}$ As mulheres são "não-toda" regidas pela lógica fálica $\left(\mathrm{Vx} \Phi \mathrm{x}^{5}\right)$,, o que significa o mesmo que dizer que as mulheres basculam entre duas lógicas de gozo: uma, orientada para o falo, como mostra o vetor que

${ }^{4}$ Não existe ao menos um $x$ tal que a função fálica não se aplica ao $\mathrm{x}$.

${ }^{5}$ Para não todo $\mathrm{x}$ é verdadeiro que a função fálica se aplica ao $\mathrm{x}$.

${ }^{6} \mathrm{O}$ significante de uma mulher, ou seja, as mulheres devem ser tomadas uma a uma. 
vai LA $^{6}$ em direção ao falo $(\Phi)$, onde supomos o que se configura como sendo a feminilidade, bem como as insígnias relativas à mascarada que designamos como sendo o gozo fálico propriamente feminino; e outra para o gozo feminino, que seria um gozo suplementar, gozo a mais que, como gostaríamos de sublinhar, não ultrapassa o vetor de corte, se situando, portanto, apenas do lado feminino, tal como é representado na parte inferior direita da tábua pelo vetor que vai de LA em direção ao significante que falta no Outro $S(A)$.

Como indicamos acima, também na perspectiva da fantasia não há relação biunívoca, correspondente da fantasia masculina para a feminina. Se, da posição homem, o sujeito se dirige ao feminino situando-o como objeto causa de seu desejo, da posição mulher, o sujeito não se dirige ao sujeito homem como causa de seu desejo, fazendo retornar o vetor a $->\$$. Nesse (des)encontro, ela, da posição não de objeto, mas advertida quanto à privação, busca um meio de se fazer representar se dirigindo ao falo. (LA-> $\Phi$ ) $\mathrm{O}$ que ela visa não é o que o sujeito posicionado como homem pode lhe dar, mas uma via de aceder ao $\Phi$ (falo), enquanto meio de representação do mistério de Ser. Assim, a fantasia que sustenta a peculiaridade do gozo fálico da mulher indica que o gozo feminino passa pelo jogo significante, no qual o falo tem 766 sua função, mas não se reduz a ele.

O feminino não se reduz a um modo de gozar. Como não há um significante que represente A Mulher e delimite o feminino, há um ilimitado que participa do gozo feminino. Podemos pensar que é essa não delimitação, que vocaciona o sujeito posicionado do lado feminino, a lidar com o ilimitado do amor tanto pela via do júbilo, quanto pela via da devastação. Quando ela ama, ele é Deus para ela. Ela ama mais além. O que marca certa condição de vulnerabilidade do sujeito que se coloca do lado feminino, mas, com a mesma potência, aponta o ilimitado. Isso é o que indica o outro vetor relativo ao gozo propriamente feminino, que, sem transpor o corte da sexuação, resta fora-do-sexo, fora da divisão, fazendo o trajeto de $A->S(A)$. Configura-se assim, no campo da fantasia feminina, tanto um gozo que visa o Phallus pela via de paradoxalmente buscar algo que represente o feminino, e responda sobre a feminilidade, quanto um gozo Outro, suplementar, alheio ao falo, remetido ao ilimitado. Gozo mais além do que aquilo que orienta a subjetivação, e, por isso mesmo, pressuposto de maneira lógica, hipotética, dado que nele o sujeito está fora.

$\mathrm{O} \mathrm{S}(\mathrm{A})$ - forma de Lacan cifrar paradoxalmente a presença do Significante da falta no campo do Outro —-, situando-o do lado feminino da tábua, vem sinalizar não a relação com a completude que a referência ao falo visa, mas, ao contrário, a marca do que nos falta para sermos plenos e 


\section{LITERATURA, ARTE, CULTURA}

a possibilidade de se gozar com isso, fazendo da falta não um viés de sofrimento, mas de abertura, trazendo a possibilidade de encontrar nisso algum júbilo, evidenciando-se sua dimensão de suplementação.

Daí Lacan (1972-73/2008c) designá-lo como hors-sexe (fora-do-sexo), isto é, não comportando divisão, fica referido ao infinito e ao ilimitado, orientado mais além do princípio do prazer. Enquanto gozo suplementar, o gozo Outro, dito feminino, incide justamente onde o gozo sexual, por ser limitado, rateia, mostrando-se insuficiente "para sustentar a relação do humano com a amplitude da existência", daí ser um gozo a mais (p. 59).

A relação do gozo feminino com o mais além indica sua relação à pulsão de morte. Ao contrário da pulsão de vida, que é sempre ruidosa, a pulsão de morte é invisível, silenciosa e autônoma. Como pulsão de destruição, que se situa além da representação, ela atua no sentido de provocar o rompimento da ordem estabelecida, das configurações esperadas, para possibilitar a emergência de novas formas. A pulsão de morte não se refere à extinção radical da vida, mas sim à morte como parte dela mesma, dado que ela só pode ser pensada se articulada a representações, ainda que seja irrepresentável. Lacan salienta que a pulsão de morte é uma "sublimação criacionista" de Freud - a sublimação de um suposto "instinto de morte", que é operada pelo corte estabelecido pela linguagem e pelo simbólico, na relação do humano com o real. Com isso, esse autor inaugura um modo de pensar sobre a origem do sujeito que se situa num ponto de "criação ex-nihilo", do qual se origina "o que é histórico na pulsão" (Lacan, 1959-60/2008a, pp. 255-256).

Assim, para Lacan, tudo que se possa imaginar em termos de existência humana deve ter como ponto de partida a ação da cadeia significante no mundo natural (Maurano, 1995, p. 137). Por isso, é necessário também interrogar tudo que está aquém e além da linguagem e do simbólico. Essa é a perspectiva que a pulsão de morte inaugura, ou seja, a dimensão do ex-nihilo como campo de investigação psicanalítico.

Talvez seja por isso que o gozo feminino, marcando essa heteridade em relação ao fálico, em razão de ele escapar a qualquer tentativa de representação, compareça como algo tão obscuro e enigmático, como um continente negro rumo ao qual navegamos sem saber o que encontraremos.

Tais perspectivas abrem caminho para supormos a existência de duas dimensões na vivência do gozo feminino: a dimensão do gozo Outro experimentado da posição mulher, gozo suplementar que pode ser motivo de celebração, e outra, relacionada à experiência do gozo do Outro como um atropelamento, podendo desembocar no aniquilamento subjetivo. Para 
representar a experiência invasiva que corresponde ao que supomos como sendo o gozo do Outro, vamos propor um acréscimo na tábua da sexuação construída por Lacan (1972-73/2008c, p. 84), que reproduzimos abaixo.

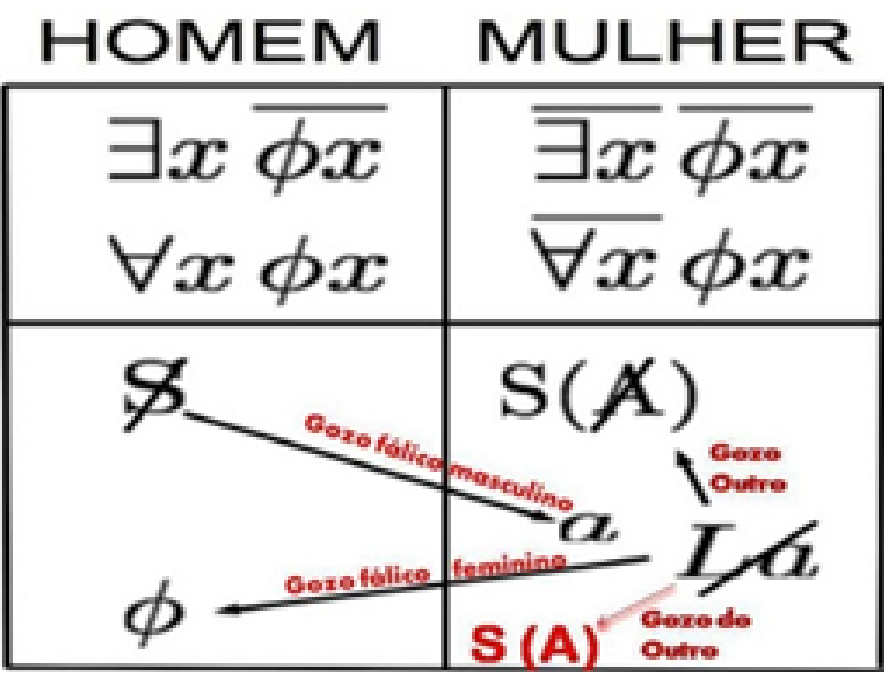

Figura 2 - Tábua da sexuação modificada

Como é possível verificar, ainda do lado feminino, no qual o vetor não ultrapassaria a linha de corte para o lado masculino, sugerimos a inclusão de outro vetor que iria de LA a S(A), ou seja, iria desse limite da representação que caracteriza o feminino em sua íntima relação com o Real, até a paradoxal ideia do Significante do Outro não barrado, formalizando, com isso, não a experiência do gozo Outro, mas sim do gozo do Outro - um gozo invasor e intrusivo atribuído a um Outro vivido como Absoluto e devastador - , como se verifica nas psicoses, configurando o que Lacan propôs designar como empuxo-à-mulher (pousse à la femme) (Lacan, 1973/2003, p. 466), ou como empuxo-ao-feminino, num sentido mais amplo do que o da experiência da emasculação.

A conceitualização do gozo do Outro nos parece operativa no que concerne à questão de tentar trazer alguma luz à incidência da violência direcionada às mulheres, bem como a toda uma camada da sociedade que se alinha com algo da posição feminina. Diante de todo o exposto acima, nos 


\section{LITERATURA, ARTE, CULTURA}

parece que, em certas condições peculiares, o remetimento ao feminino experimentado e recusado em si mesmo, promovendo ou ameaçando promover um aniquilamento fálico em sujeitos posicionados do lado homem, incita uma destituição subjetiva que favorece a experiência da intrusão do gozo do Outro, mobilizando defesas radicais como a aniquilação e a morte do feminino no outro, donde o feminicídio é uma de suas expressões. Trata-se aí de eliminar, a todo custo, o feminino, nem que para isso o sujeito tenha que até mesmo eliminar a si mesmo. Em certos casos, também o apassivamento relativo à experiência amorosa pode ser vivido como elemento insuportável de feminização e em certas condições patológicas trazer à cena consequências nefastas do horror ao feminino. Nesse sentido, talvez possam ser incluídas nesse mesmo contexto o horror às chamadas minorias, que, presentificando a despossessão, ameaçam o império fálico e sofrem as consequências disso. No entanto, essa última perspectiva não foi explorada neste trabalho.

Privilegiamos a contribuição da teoria lacaniana acerca da relação do sujeito ao gozo como instrumento para refletirmos sobre esse dado que, atravessando a história e o tempo, nos oferece fartos testemunhos da memória da violência contra o que achamos mais preciso designar como o feminino na mulher. A teoria dos gozos em Lacan favorece uma abordagem mais direta das pulsões, destacando a dimensão econômica do psiquismo, em sua intrincada relação com o que é da ordem do prazer e o que se encontra mais além do princípio de prazer, sob o imperativo de satisfações de caráter paradoxal. Nessa última perspectiva, não é propriamente o desejo que está em causa, nem tampouco a dinâmica da relação com a falta que move o sujeito enquanto desejante na orientação de uma ação, mas imperativo cego no qual o sujeito está fora de cena, ainda que momentaneamente.

Talvez possamos pensar, ainda, que tal violência contra o feminino na mulher seja favorecida culturalmente por um modo de construção da masculinidade que, movido pela sideração fálica, incita o repúdio ao feminino. Qualquer proximidade com o feminino pode despertar no sujeito defendido por seu atrelamento narcísico ao falo e às insígnias de poder viril que extrai disso uma posição de tal horror em razão do medo da perda dessa identificação viril, que reage a essa ameaça com o intuito de aniquilar a diferença. Ante ao empuxo-à-mulher, ou empuxo-ao-feminino, o sujeito responde com o aniquilamento do feminino na mulher, seja essa anulação concretizada por violências corporais, seja por violências psicológicas. O que o sujeito não pode suportar é a tentação advinda do que suscita a possibilidade de um gozo feminino, fora do domínio fálico vivido como mal vindo, inadequado, aterrorizante. O risco 
eminente do qual o sujeito se defende é o de sair do lado homem e cair no lado mulher, como se estivesse sendo aspirado, pelo gozo do Outro, para o lado mulher da tábua da sexuação, que é onde Lacan situa o feminino.

A hipótese que sustentamos é que a devastação no masculino é vivida como uma invasão na qual o sujeito experimenta a despossessão não consentida de si mesmo. A emergência da angústia extrema é capaz de provocar a queda das identificações simbólico-imaginárias que estruturam o narcisismo fálico do sujeito, ocasionando a perda momentânea da realidade, que o remete para fora do universo das representações.

A angústia experienciada na devastação, não como angústia de castração, mas como angústia de aniquilamento - que implica a invasão do real no imaginário - , torna a fantasia inoperante, fazendo com que o sujeito não consiga estabelecer, minimamente, uma mediação em relação ao Outro ora vivido como Absoluto, que o subjuga e o torna passivo, emasculado diante de um gozo avassalador. Como observamos acima, a experiência amorosa pode, muito bem, desencadear esse quadro. É interessante pensarmos que o que desenvolvemos aqui é consoante com o que comparece na sabedoria popular indicando que tanto ódio ao feminino, evidenciado inclusive nas homofobias, e outras manifestações similares, faz suspeitar de sua "atração fatal" por ele e seu consequente repúdio defensivo.

Se, por um lado, a violência contra a mulher pode ser vista como um modo defensivo de o sujeito se posicionar frente à emergência imperativa da posição feminina, respondendo com a tentativa de aniquilamento, por outro, talvez possamos supor que o suicídio cometido por alguns sujeitos logo após terem praticado o feminicídio pode evidenciar a experiência de queda total do lado do feminino. Tais sujeitos, frente ao real insuportável, enxergam na morte a única solução possível para barrar o gozo do Outro. Contudo, não estamos sugerindo que todos os casos de suicídio teriam esse fator como desencadeador, mas sim, possivelmente, nos casos em que o feminicídio é seguido pelo suicídio do autor.

\section{Referências}

Braunstein, N. (2007). Gozo. São Paulo, SP: Escuta.

Cruz, São João (1960) Obras completas. Vol. I. Petrópolis, RJ: Vozes0. Disponível em em https://www.academia.edu/34036685/Obras_de_S\%C3\%A3o_Jo\%C3\%A3o_ da_Cruz_Vol_I. (acesso em 13/05/2021). (Trabalho original publicado em 1578). 


\section{LITERATURA, ARTE, CULTURA}

Freud, S. (2006a). Três ensaios sobre a teoria da sexualidade. In Edição Standard Brasileira das Obras Psicológicas Completas de Sigmund Freud (Vol. VII). Rio de Janeiro, RJ: Imago. (Trabalho original publicado em 1905).

Freud, S. (2006b). Minhas teses sobre o papel da sexualidade na etiologia das neuroses. In Edição Standard Brasileira das Obras Psicológicas Completas de Sigmund Freud (Vol. VII). Rio de Janeiro, RJ: Imago. (Trabalho original publicado em 1906).

Freud, S. (2006c). Notas psicanalíticas sobre um relato autobiográfico de um caso de paranoia. In Edição Standard Brasileira das Obras Psicológicas Completas de Sigmund Freud (Vol. XII). Rio de Janeiro, RJ: Imago. (Trabalho original publicado em 1911).

Freud, S. (2006d). Totem e tabu. In Edição Standard Brasileira das Obras Psicológicas Completas de Sigmund Freud (Vol. XIII). Rio de Janeiro, RJ: Imago. (Trabalho original publicado em 1913).

Freud, S. (2006e). Pulsões e destinos da pulsão. In Edição Standard Brasileira das Obras Psicológicas Completas de Sigmund Freud (Vol. XIV). Rio de Janeiro, RJ: Imago. (Trabalho original publicado em 1915).

Freud, S. (2006f). Além do princípio de prazer. In Edição Standard Brasileira das Obras Psicológicas Completas de Sigmund Freud (Vol. XVIII). Rio de Janeiro, RJ: Imago. (Trabalho original publicado em 1920).

Freud, S. (2006g). Projeto para um psicologia científica. In Edição Standard Brasileira das Obras Psicológicas de Sigmund Freud (Vol I.) Rio de Janeiro, RJ: Imago. (Trabalho Originalmente publicado em 1895).

Freud, S. (2018a). Algumas consequências psíquicas da distinção anatômica entre os sexos. In Amor, sexualidade, feminilidade. Belo Horizonte, MG: Autêntica. (Trabalho original publicado em 1925).

Freud, S. (2018b). Sobre a sexualidade feminina. In Amor, sexualidade, feminilidade. Belo Horizonte, MG: Autêntica. (Trabalho original publicado em 1931).

Freud, S. (2018c). Conferência XXXIII - Feminilidade. In Amor, sexualidade, feminilidade. Belo Horizonte, MG: Autêntica. (Trabalho original publicado em 1933).

Freud, S. (2019). O Infamiliar [Das Unheimliche]. Belo Horizonte, MG: Autêntica. (Trabalho original publicado em 1919).

Lacan, J. (1988). O seminário. Livro 3. As psicoses. Rio de Janeiro, RJ: Zahar. (Trabalho original publicado em 1955-56).

Lacan, J. (1998). A significação do falo. In Escritos. Rio de Janeiro, RJ: Zahar. (Trabalho original publicado em 1958).

Lacan, J. (2003). O Aturdito. In Outros escritos. Rio de Janeiro, RJ: Zahar. (Trabalho original publicado em 1973). 
Lacan, J. (2005). O seminário. Livro 10. A angústia. Rio de Janeiro, RJ: Zahar. (Trabalho original publicado em 1963).

Lacan, J. (2008a). O seminário. Livro 7. A ética da psicanálise. Rio de Janeiro, RJ: Zahar. (Trabalho original publicado em 1959-60).

Lacan, J. (2008b). O seminário. Livro 11. Os quatro conceitos fundamentais da psicanálise. Rio de Janeiro, RJ: Zahar. (Trabalho original publicado em 1964).

Lacan, J. (2008c). O seminário. Livro 20. Mais ainda. Rio de Janeiro, RJ: Zahar. (Trabalho original publicado em 1972-73).

Maurano, D. (1995). Nau do desejo. Rio de Janeiro, RJ: Relume-Dumará.

Maurano, D. (2001). A face oculta do amor: a tragédia à luz da psicanálise. Rio de Janeiro, RJ: Imago Editora/Ed. UFJF.

Maurano, D. (2006). A transferência: uma viagem rumo ao continente negro. Rio de Janeiro, RJ: Zahar.

Maurano, D. (2011). Torções: a psicanálise, o barroco e o Brasil. Curitiba, PR: Editora CRV.

Maurano, D., \& Albuquerque, B. (2019, setembro). Lacan e a experiência mística à luz da psicanálise. Revista Latinoamericana de Psicopatologia Fundamental, 22 (3), 439-456.

Maurano, D., \& souza, J. (2017). Memórias da misoginia e do feminicídio: expressões do horror ao feminino? Trabalho apresentado no VII Encontro Nacional e VII Colóquio Internacional do Corpo Freudiano Escola de Psicanálise, realizado em novembro de 2017 em São Luiz, MA.

Pommier, G. (2014). Féminin, révolution sans fin. Paris, FR: Pauver.

Schereber, D. P. (2006). Memórias de um doente dos nervos. Rio de Janeiro, RJ: Terra e Paz. (Trabalho original publicado em 1903).

Vivès, J.-M. (2003). La vocation du féminin. Cliniques méditerranéennes, 68, 193-205, 2003/2. Recuperado em 1 out.2018 de: <https://www.cairn.info/revuecliniques-mediterraneennes-2003-2-page-193.htm $>$.

Vivès, J.-M. (2002). La voi(x)e du féminin: entre regard et invocation. In A. Juranville, \& J. André (Dir.), Fatalités du féminin. Paris, FR: Presses Universitaires de France.

Zalcberg, M. (2007). Amor paixão feminina. Rio de Janeiro, RJ: Elsevier. 


\section{LITERATURA, ARTE, CULTURA}

\section{Resumos}

(Devastation in the masculine and violence against feminine in women)

This article aims to provide some contributions from psychoanalysis to clarify the issue of violence against women, a phenomenon that has occurred repeatedly in the history of societies. To analyze the structural bases of that kind of violence, we resort to the Lacanian theory of phallic jouissance and Other jouissance, feminine, proposing a differentiation between what is supposed to be Other jouissance and what is established as jouissance of the Other. Following the path proposed by Lacan, we suggest the hypothesis that jouissance of the Other may be related to the experience by the subject positioned on the masculine side, of an intrusive and devastating jouissance attributed to an Other, lived as absolute, mobilizing misogynous and even feminicide reactions. This distinction was operative in the sense that it allowed us to think about what we call here "devastation in the masculine" and its possible relationship with what we discern as "violence against the feminine in women" in this article.

Key words: Devastation, feminine, masculine, jouissance

(Dévastation chez le masculin et violence faite au féminin chez les femmes)

Cet article vise à apporter quelques contributions de la psychanalyse pour adresser la question de la violence contre les femmes, phénomène qui se répète dans l'histoire des sociétés. Cherchant à réfléchir sur les fondements structurels de cette violence, nous recourons à la théorie lacanienne des jouissances phalliques et de la jouissance Autre, féminine, proposant une différenciation entre ce qui est supposé être la jouissance Autre et ce qui s'établit comme jouissance de l'Autre. En suivant la voie ouverte par Lacan, nous avançons l'hypothèse que la jouissance de l'Autre pourrait être liée à l'expérience du sujet positionné du côté masculin, d'une jouissance intrusive et dévastatrice attribuée à un Autre vécu comme absolu, mobilisant des réactions misogynes et même féminicides. Cette distinction était opérative dans le sens qu'elle nous permettait de penser ce que nous désignons ici comme la " dévastation chez le masculin " et sa relation possible avec ce que nous discernons dans l'article comme "violence contre le féminin chez la femme ».

Mots clés: Dévastation, féminin, masculin, jouissance

(Devastación en lo masculino y la violencia contra lo femenino en las mujeres)

Este artículo tiene como objetivo presentar algunos aportes del psicoanálisis para aclarar el tema de la violencia contra la mujer, un fenómeno que se repite en la historia de las sociedades. Buscando reflexionar sobre las bases estructurales de esta violencia, recurrimos a la teoría lacaniana del goce fálico y del goce Otro, femenino, proponiendo una diferenciación entre lo que se supone que es el goce Otro y lo que 
se establece como goce del Otro. Siguiendo el camino abierto por Lacan, lanzamos la hipótesis de que el goce del Otro puede estar relacionado con la experiencia del sujeto ubicado al lado de lo masculino, de un goce intrusivo y devastador atribuido a un Otro vivido como absoluto, movilizando reacciones misóginas e incluso feminicidas. Esta distinción fue pertinente para permitirnos pensar en lo que designamos aquí como "devastación en lo masculino” y su posible relación con lo que en el artículo discernimos como "violencia contra lo femenino en la mujer".

Palabras clave: Devastación, femenino, masculino, goce

Citação/Citation: Mello, D. M., \& Souza, J. D. da S. (2021, dez.). A devastação no masculino e a violência contra o feminino nas mulheres. Revista Latinoamericana de Psicopatologia Fundamental, 24(4), 749-775. http://dx.doi.org/10.1590/1415-4714.2021v24n43p749.13

Editora/Editor: Profa. Dra. Sonia Leite

Submetido/Submitted: 23.5.2021/5.23.2021 Aceito/Accepted: 2.8.2021 / 8.2.2021

Copyright: (C) 2009 Associação Universitária de Pesquisa em Psicopatologia Fundamental/ University Association for Research in Fundamental Psychopathology. Este é um artigo de livre acesso, que permite uso irrestrito, distribuição e reprodução em qualquer meio, desde que o autor e a fonte sejam citados / This is an open-access article, which permits unrestricted use, distribution, and reproduction in any medium, provided the original authors and sources are credited.

Financiamento/Funding: Este trabalho não recebeu apoio. / This work received no funding.

Conflito de interesses/Conflict of interest: As autoras declaram que não há conflito de interesses. / The authors have no conflict of interest to declare.

\section{Denise Maurano Mello}

Doutora em filosofia pela Universidade Paris XII (Paris, França)/Pontificia Universidade Católica do Rio de Janeiro - PUC -Rio (Rio de Janeiro, RJ, Br), com estágio pós-doutoral em Letras pela PUC-Rio; Professora titular aposentada do Programa de Pós-Graduação em Memoria Social e da Escola de Direito da Universidade Federal do Estado do Rio de Janeiro - UNIRIO (Rio de Janeiro, RJ, Br); Editora de Psicanálise \& Barroco em revista; Psicanalista membro do Corpo Freudiano Escola de Psicanálise - Seção Rio de Janeiro (Rio de Janeiro, RJ, Br).

Rua Hermenegildo de Barros, 27 - Santa Teresa

20241-040 Rio de Janeiro, RJ, Br

dmaurano@corpofreudiano.com.br

https://orcid.org/0000-0003-3498-3773 


\section{LITERATURA, ARTE, CULTURA}

JoAna Dark da Silva Souza

Psicanalista; Doutora em Memória Social pela Universidade Federal do Estado do Rio de Janeiro - UNIRIO (Rio de Janeiro, RJ, Br); Doutora em Psicologia Clínica pela Université Côte d' Azur - UNICE (Nice, França); Diretora do Corpo Freudiano Escola de Psicanálise Núcleo Teresópolis. Gerente de Edição do periódico Psicanálise e Barroco em revista.

Rua Senador Vergueiro, 219 - Flamengo

22230-000 Rio de Janeiro, RJ, Br.

joanapsi@uol.com.br

https://orcid.org/0000-0003-4294-2883

This is an open-access article, which permits unrestricted use, distribution, and reproduction in any medium for non-commercial purposes provided the original authors and sources are credited. 